\title{
NF-KB, iNOS, IL-6, and collagen 1 and 5 expression in healthy and keratoconus corneal fibroblasts after $0.1 \%$ riboflavin UV-A illumination
}

\author{
Tim Berger $^{1}$ (D) Nóra Szentmáry ${ }^{2}$ - ${\text { Lorenz } \text { Latta }^{2} \text { • Berthold Seitz }}^{1}$ - Tanja Stachon ${ }^{1,2}$ \\ Received: 26 August 2020 / Revised: 12 December 2020 / Accepted: 18 December 2020 / Published online: 14 January 2021 \\ (C) The Author(s) 2021
}

\begin{abstract}
Purpose To analyze the effect of riboflavin UV-A illumination on mRNA and protein expression of healthy (HCFs) and keratoconus human corneal fibroblasts (KC-HCFs), concerning the inflammatory markers NF- $\mathrm{KB}$, iNOS, IL-6, and collagen 1 and 5 (Col 1/Col 5). Methods Keratocytes were isolated from healthy $(n=3)$ and keratoconus $(\mathrm{KC})$ corneas $(n=3)$ and were cultivated in basal medium with 5\% fetal calf serum, which resulted in their transformation into human corneal fibroblasts ( $\mathrm{HCFs} / \mathrm{KC}-\mathrm{HCFs})$. Cells underwent $0.1 \%$ riboflavin UV-A illumination for $250 \mathrm{~s}(\mathrm{CXL})$. NF-kB, iNOS, IL-6, Col 1, and Col 5 expression was investigated by qPCR and Western blot analysis. IL- 6 concentration of the cell culture supernatant and cell lysate was determined by ELISA.

Results In untreated KC-HCFs, NF-KB $(p=0.0002)$, iNOS $(p=0.0019)$, Col $1(p=0.0286)$, and Col $5(p=0.0054)$ mRNA expression was higher and IL-6 expression was lower $(p=0.0057)$, than in healthy controls. In HCFs, CXL led to an increased NF-KB $(p=0.0286)$ and IL-6 $(p=0.0057)$ mRNA expression. The IL-6 concentration in the cell culture supernatant was increased in HCFs $(p=0.0485)$ and KC-HCFs $(p=0.0485)$ after CXL. CXL increased intracellular IL-6 concentration only in KC-HCFs $(p=0.0357)$. In the HCF group ( $p=0.0286)$, an increased Col 1 mRNA expression after CXL could be observed. Conclusion Our study confirmed altered gene expression in untreated KC-HCFs compared to untreated HCFs. Riboflavin UV-A illumination affected gene expression only in HCFs. Increased IL-6 concentration in the cell culture supernatant and cell lysate indicate a secondary inflammatory response of $\mathrm{HCFs}$ and $\mathrm{KC}-\mathrm{HCF}$ s to riboflavin UV-A illumination.
\end{abstract}

\section{Key messages:}

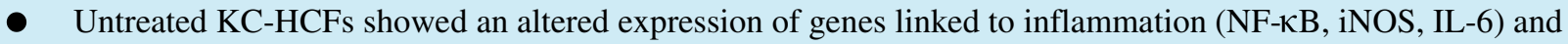
increased mRNA expression of the collagens (Col 1 and 5) in contrast to untreated HCFs.

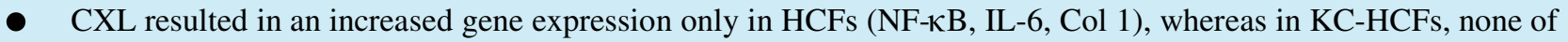
the investigated genes showed expression changes after this treatment.

- Increased IL-6 concentration in the cell cultures upernatant of HCFs and KC-HCFs and an increased intracellular IL-6 concentration in KC-HCFs indicate an inflammatory response after CXL.

- This study show that KC-HCFs possess an altered gene and protein expression compared to HCFs before and after CXL.

Tim Berger

tim.berger@uks.eu

1 Department of Ophthalmology, Saarland University Medical Center, Kirrberger Str. 100, D-66424 Homburg, Saar, Germany

2 Dr. Rolf M. Schwiete Center for Limbal Stem Cell and Aniridia Research, Saarland University, Homburg, Saar, Germany 
Keywords Keratoconus $\cdot$ Cross-linking $\cdot$ Corneal fibroblast $\cdot$ Inflammation $\cdot$ Collagen

\section{Introduction}

Keratoconus (KC) is a bilateral, progressive ectatic corneal disease, which results in a cone-shaped protrusion of the corneal tissue due to the thinning of the corneal stroma. These morphological changes are associated with reduced visual acuity, progressive myopia, and irregular astigmatism. As part of the progressive stromal thinning in advanced $\mathrm{KC}$, the rupture of Descemet's membrane may cause an acute hydrops. This stromal edema subsequently results in corneal scarring, which makes penetrating keratoplasty in most cases necessary in order to improve visual acuity [1].

In general, an annual incidence of 2/100,000 and a prevalence of 54.5/100,000 is assumed [2]. These data are based on a long-term study from 1935 to 1982 and may be outdated due to progress in diagnostics. A recent study indicates that the annual incidence $(13.3 / 100,000)$ and the prevalence $(265 /$ $100,000)$ could be 5 -fold higher than previously reported [3]. Although $\mathrm{KC}$ is known to affect all ethnic groups, its development shows geographical variability with a higher incidence among the Asian population [4].

The etiology of $\mathrm{KC}$ has not been clarified so far, but a complex, multifactorial pathogenesis is assumed. In most cases, $\mathrm{KC}$ occurs as an isolated disease without any evidence of underlying concomitant diseases. KC shows a higher familial incidence, which could be an indicator of a genetic predisposition. Biochemical alterations associated with increased proteolytic activity are discussed to be responsible for the degradation of corneal structural components resulting in the biomechanical weakening of the cornea. It is also assumed that a different distribution and lower number of stromal lamellae in $\mathrm{KC}$ is associated with reduced corneal rigidity and thinning, compared to normal corneas. Besides, $\mathrm{KC}$ is more frequent in Down syndrome, Leber's congenital amaurosis, Ehlers-Danlos syndrome, and osteogenesis imperfecta [5].

Although $\mathrm{KC}$ is classified in the common literature as a non-inflammatory disease, there are data referring to potential underlying inflammatory components. In a previous study of our research group, increased nuclear factor kappa B p65 (NF-KB) mRNA and protein expression, and an increased inducible NO synthase (iNOS) mRNA expression could be verified in human keratoconus fibroblasts (KC-HCFs), compared to healthy controls, which refers to corneal inflammation in KC [6]. In addition, an increased interleukin-6 (IL-6), tumor necrosis factor- $\alpha$ (TNF- $\alpha$ ), and matrix metalloprotease9 (MMP-9) concentration could be measured in tear fluid of $\mathrm{KC}$ patients, and a higher concentration of these proteins was associated with a more severe form of KC [7]. Besides, several studies have demonstrated increased oxidative stress and altered metabolism in $\mathrm{KC}$ stromal cells $[8,9]$.

The healthy corneal stroma is rich in collagen $1 \mathrm{~A} 1(\mathrm{Col} 1)$ and contains a relatively large amount of type 5A1 collagen ( $\mathrm{Col} \mathrm{5).}$ Corneal collagen fibrils consist of type I collagen molecules that are integrated into heterotypic fibrils together with type 5 collagen. These interactions ensure the proper organization of the collagen lamellae and regulate the diameter of the collagen fibrils to maintain corneal transparency [10]. It has been shown that $\mathrm{KC}$ is associated with altered collagen fibrillar diameter, alterations in collagen distribution, and changes in fibril orientation within the corneal stroma [11, 12].

Conservative and surgical $\mathrm{KC}$ treatment options depend on the progression of the disease. In the early stages, refractive changes can be corrected using spectacles or contact lenses. Minimally invasive surgical treatment options include corneal collagen cross-linking (CXL) and the implantation of intracorneal ring segments, using these two surgical treatment options either separately or in combination. In advanced stages, either lamellar or penetrating keratoplasty could be necessary [13].

The aim of CXL is to increase the stiffness of the corneal tissue by forming further bonds between the collagen fibrils. Therefore, the simultaneous use of riboflavin (vita$\min \mathrm{B}_{2}$ ) as a photosensitizer and a $370-\mathrm{nm}$ wavelength UV-A light leads to cross-links between the collagen fibrils due to a photochemical reaction, resulting in stabilization of the current state [14].

Riboflavin is excited by absorbing energy of the UV-A light (singlet riboflavin), and it is converted into a triplet state. Type I and type II reactions can be distinguished. For the type II reaction, oxygen is required to form singlet oxygen, an oxygen radical, which react with the carbonyl group of the collagen [14]. The type I reaction takes place after that the oxygen is exhausted, in which the excited riboflavin (triplet state) is transferring a hydrogen atom or electron to biomolecules such as lipids, proteins, and nucleic acids or generates reactive oxygen species (ROS) like superoxide anion, hydroxyl radical, or hydrogen peroxide [15]. As a consequence of these reactions, the collagen fibrils are cross-linked, and thus, the current stage of the disease is stabilized.

The first clinical results of CXL were published in 2003 by Wollensak et al. to conclude that the progression of $\mathrm{KC}$ could be slowed down [16].

Nowadays, CXL represents an important therapeutic option for KC patients, but the cellular effects are not well understood. In a previous study, we have shown that riboflavin UV-A illumination is associated with increased apoptosis and decreased viability of keratoconus stromal cells [17]. 
In the present work, our purpose was to analyze the effects of riboflavin UV-A illumination on mRNA and protein expression of healthy (HCFs) and keratoconus human corneal fibroblasts (KC-HCFs), concerning the inflammatory markers NF- $\mathrm{BB}$, iNOS, IL-6, and collagen 1 and $5(\mathrm{Col} \mathrm{1/Col} \mathrm{5).} \mathrm{As} \mathrm{a} \mathrm{first} \mathrm{step,}$ our purpose was to investigate NF-kB, iNOS, IL-6, and Col 1/ Col 5 mRNA and protein expression differences between untreated healthy and $\mathrm{KC}$ human corneal fibroblasts. As a second step, we aimed to investigate the inflammatory response (NF- $\mathrm{B}$, iNOS, IL-6) related to the increased free oxygen species formation after riboflavin UV-A illumination in these cells. Thirdly, we aimed to examine whether a riboflavin UV-A illumination has an impact on Col 1/Col 5 expression.

\section{Materials and methods}

\section{Ethics approval and consent to participate}

This study was performed in accordance with the Declaration of Helsinki and was approved by the Ethics Committee of Saarland/Germany (No. 41/18). An informed consent was obtained from all participants with $\mathrm{KC}$, before keratoplasty was performed.

\section{Cell culture}

Three normal human corneas were obtained from the LIONS Cornea Bank Saar-Lor-Lux, Trier/Westpfalz. Donor corneoscleral buttons, which did not match the criteria for transplantation (less than 1800 endothelial cells $/ \mathrm{mm}^{2}$ ), have been used for the experiments. In addition, central corneal buttons with a diameter of $8.0 \mathrm{~mm}$ were obtained from elective penetrating keratoplasties of $3 \mathrm{KC}$ patients who did not undergo previous ocular surgery. Immediately after elective penetrating keratoplasty, the explanted corneal buttons were further processed for cell cultivation. The donor corneoscleral buttons were explanted within $24 \mathrm{~h}$ postmortem. As these corneas were not considered suitable for elective keratoplasty, they were released for study purposes. Therefore, three healthy human corneas and three corneas from $\mathrm{KC}$ patients were used for cell cultivation. Further information on donor corneoscleral buttons and $\mathrm{KC}$ patients is provided in Tables 1 and 2.
Cell culture work was performed under sterile conditions. The donor corneoscleral buttons were first rinsed in phosphate-buffered saline (PBS) (Sigma-Aldrich, St. Louis, USA); then, adjacent scleral parts with $2 \mathrm{~mm}$ of the clear cornea were removed, and the central corneal button was cut into pieces using a disposable surgical scalpel. For isolation of the keratocytes, the tissue was incubated with $1.0 \mathrm{mg} / \mathrm{ml}$ collagenase A (Hoffmann-La Roche, Basel, Switzerland) together with cell culture medium consisting of Dulbecco's modified Eagle's medium (DMEM/F12) (Thermo Fisher Scientific, Waltham, MA, USA), $5 \%$ fetal calf serum (FCS) (Thermo Fisher Scientific, Waltham, MA, USA), and $1 \%$ penicillinstreptomycin (P/S) (Sigma-Aldrich, St. Louis, USA) for $24 \mathrm{~h}$ at $37{ }^{\circ} \mathrm{C}$, which is a common standard procedure for fibroblast cell culture work. The above-mentioned mixture (DMEM/F12, FCS, P/S) is defined in the following text as cell culture medium. The digested tissue and cells were centrifuged at $800 \mathrm{~g}$ for $7 \mathrm{~min}$, and the supernatant was discarded. After resuspending the cell pellet with $1 \mathrm{ml}$ PBS, the cell suspension was seeded in a $75-\mathrm{cm}^{2}$ cell culture flask containing $13 \mathrm{ml}$ of cell culture medium, which was changed every third or fourth day until the cells reached confluence. Cultivation was performed in an incubator at $37{ }^{\circ} \mathrm{C}$ with $95 \%$ relative humidity and $5 \% \mathrm{CO}_{2}$ atmosphere. The confluent cell culture was harvested with trypsin EDTA (Sigma-Aldrich, St. Louis, USA) and was split into several $75-\mathrm{cm}^{2}$ cell culture flasks. The influence of the FCS resulted in a differentiation of the keratocytes into fibroblasts. Therefore, we specify them further on as "human corneal fibroblasts" (HCFs) and "keratoconus human corneal fibroblasts" (KC-HCFs). Experiments were performed using passages three to eight of the cells.

\section{Riboflavin UV-A illumination of HCFs and KC-HCFs}

The cell culture medium was changed $24 \mathrm{~h}$ before starting the experiments. Riboflavin (Sigma-Aldrich, St. Louis, USA) was diluted with cell culture medium to a concentration of $0.1 \%$, was protected from light, and was stored at $4{ }^{\circ} \mathrm{C}$ for the experiments (further on "riboflavin solution").

Table 1 Descriptive data of donor corneoscleral buttons

\begin{tabular}{llllll}
\hline & Donor age (years) & Gender & Side & Cause of death & Exclusion from corneal transplantation \\
\hline HCF 1 & 81 & Female & Right & Intracranial hemorrhage & $<1800$ endothelial cells/mm ${ }^{2}$ \\
HCF 2 & 90 & Male & Right & Bronchial carcinoma & $\begin{array}{c}\text { Used for Descemet membrane endothelial } \\
\text { keratoplasty tissue preparation }\end{array}$ \\
HCF 3 & 69 & Male & Left & Intracranial hemorrhage & $<1800$ endothelial cells/mm
\end{tabular}


Table 2 Keratoconus patient characteristics corresponding to the primary cell cultures

\begin{tabular}{lllllll} 
Patient age (years) & Gender & Side & $\begin{array}{l}\text { Keratoconus grading } \\
\text { (ABCD system, Belin) }\end{array}$ & Co-morbidities & Corneal explant size (mm) & $\begin{array}{l}\text { Time from } \\
\text { explantation to } \\
\text { cell cultivation (h) }\end{array}$ \\
\hline 51 & Male & Right & A4/B4/C4/D4+ & Arterial hypertension & 8.0 & $<12$ \\
31 & Male & Left & A4/B4/C4/D4+ & Healthy & 8.0 & $<12$ \\
36 & Female & Right & A0/B2/C4/D2+ & Healthy & 8.0 & $<12$ \\
\hline
\end{tabular}

As a first step, the cell culture supernatant was removed, and either $5 \mathrm{ml}$ cell culture medium or $5 \mathrm{ml}$ of the riboflavin solution was pipetted into the cell culture flask under the sterile bench. Thereafter, the cell culture was quickly placed in the dark or was illuminated with 375-nm UV-A light for $250 \mathrm{~s}\left(2 \mathrm{~J} / \mathrm{cm}^{2}\right)$ in an illumination box. After the immediate removal of the cell culture medium or the riboflavin solution, the flask was rinsed twice with $10 \mathrm{ml}$ PBS. We added to each cell culture $10 \mathrm{ml}$ cell culture medium, and cells were cultured for $24 \mathrm{~h}$ or $48 \mathrm{~h}$ at $37^{\circ} \mathrm{C}$ before measurements. In order to determine the IL- 6 concentration in the cell culture supernatant, $1.5 \mathrm{ml}$ cell culture supernatant was collected from each flask before harvesting of the cells $(24 \mathrm{~h}$ or $48 \mathrm{~h}$ after the experiment) and was stored at $-80{ }^{\circ} \mathrm{C}$.

Then, the cells were harvested with trypsin EDTA and were stored at $-80{ }^{\circ} \mathrm{C}$ until further use.

\section{RNA isolation and CDNA synthesis}

RNA was isolated using the RNA Purification Plus Micro Kit (Norgen Biotek Corp., Thorold, Canada), following the instructions provided by the manufacturer. RNA quantity was determined using a UV/VIS spectrophotometer (Analytik Jena AG, Jena, Germany), and the eluted RNA was stored at $-80{ }^{\circ} \mathrm{C}$ for further use.

The cDNA synthesis was performed using the OneTaq RTPCR Kit (New England BioLabs, Frankfurt a. M., Germany) according to the instructions provided for the Kit. For cDNA synthesis, $1 \mu \mathrm{g}$ of total RNA was used as template for all samples. The synthesized cDNA was stored at $-20{ }^{\circ} \mathrm{C}$ for further use.

\section{Quantitative PCR}

The reaction mix (total volume: $9 \mu \mathrm{l}$ ) for quantitative PCR (qPCR) consisted of $1 \mu$ of the specific primer solution, $5 \mu \mathrm{l} \mathrm{SYBR}$ Green Mix (Qiagen N.V., Venlo, Netherlands), and $3 \mu \mathrm{l}$ nuclease-free water. The qPCR reactions were performed using the QuantStudio 5 real-time PCR system (Thermo Fisher Scientific, Waltham, MA, USA). Samples were run in $9 \mu \mathrm{l}$ volume using $1.5 \mu \mathrm{l}$ cDNA according to the manufacturer's instructions. The amplification conditions (40 cycles) were $95^{\circ} \mathrm{C}$ for $10 \mathrm{~s}, 60^{\circ} \mathrm{C}$ for $30 \mathrm{~s}$, and $95^{\circ} \mathrm{C}$ for $15 \mathrm{~s}$. All samples were measured in duplicate. Values were normalized to Tata-binding protein (TBP) expression levels as endogenous control gene, using the $\Delta \Delta \mathrm{CT}$ method. The fold change $\left(2^{\Delta \Delta C T \text {-value }}\right)$ was used for the statistical analysis. A list of primers used for qPCR is summarized in Table 3. Normal HCFs (incubated in the dark with cell culture medium for 250 s) were used as controls (fold change $=1$ ). Gene expression was measured for predetermined time points (Table 4), which have been chosen according to previous measurement series of our research group [18].

\section{Protein quantification and Western blot analysis}

Cells were lysed in RIPA buffer (Thermo Fisher Scientific, Waltham, MA, USA) $48 \mathrm{~h}$ after the experiments, and protein concentration was determined using the Pierce ${ }^{\mathrm{TM}} \mathrm{BCA}$ Protein Assay Kit (Thermo Fisher Scientific, Waltham, MA, USA). The measurement was performed using the Tecan Infinite F50 Absorbance Microplate Reader (Tecan

Table 3 Primer pairs used for qPCR

\begin{tabular}{lll}
\hline Primer & Primer sequence or QIAGEN catalog number & Manufacturer (company, city, country) \\
\hline Collagen 1A1 (Col 1) & QT00037793 & Qiagen N.V., Venlo, Netherlands \\
Collagen 5A1 (Col 5) & QT00044527 & Qiagen N.V., Venlo, Netherlands \\
Inducible NO synthase (iNOS) & CTGGCAAGCCCAAGGTCTAT & Eurofins Genomics Germany GmbH, Ebersberg, Germany \\
Interleukin-6 (IL-6) & GGAGGCTCCGATCAATCCAG & Qiagen N.V., Venlo, Netherlands \\
Nuclear factor kappa B p65 (NF-kB) & QT00083720 & Qiagen N.V., Venlo, Netherlands \\
Tata-binding protein (TBP) & QT00000721 & Qiagen N.V., Venlo, Netherlands \\
\hline
\end{tabular}


Table 4 The examined gene expressions and the respective measurement time points, following riboflavin UV-A illumination

\begin{tabular}{ll}
\hline Gen & $\begin{array}{l}\text { Time points of gene expression } \\
\text { measurement after riboflavin UV-A illumination }\end{array}$ \\
\hline Inducible NO synthase (iNOS) & $48 \mathrm{~h}$ \\
Interleukin-6 (IL-6) & $24 \mathrm{~h}+48 \mathrm{~h}$ \\
Collagen 1A1 (Col 1) & $24 \mathrm{~h}$ \\
Collagen 5A1 (Col 5) & $24 \mathrm{~h}$ \\
Nuclear factor kappa B p65 (NF-kB) & $24 \mathrm{~h}$ \\
Tata-binding protein (TBP) & $24 \mathrm{~h}+48 \mathrm{~h}$ \\
\hline
\end{tabular}

Group AG, Männedorf, Switzerland) with 560-nm wavelength. Bovine serum albumin (BSA) was used as a standard. The measurements were performed in duplicate. For Western blot analysis, samples with $20 \mu \mathrm{g}$ total protein were boiled in a sample buffer for $5 \mathrm{~min}$ at $95{ }^{\circ} \mathrm{C}$ and were loaded on a precast $4-12 \%$ NuPage $^{\mathrm{TM}}$ Bis-Tris SDS Gel (Invitrogen, Waltham, MA, USA). The first well was loaded with $3 \mu$ Precision Plus Protein ${ }^{\mathrm{TM}}$ Dual Color Standard (Bio-Rad Laboratories, Hercules, USA) to determine the molecular weight. NuPAGETM MOPS SDS Running Buffer $(20 \times)$ (Thermo Fisher Scientific, Waltham, MA, USA) was used as an electrophoresis buffer. After protein separation, semi-dry blotting on a nitrocellulose membrane was performed using the Trans-Blot Turbo Transfer System (Bio-Rad Laboratories, Hercules, USA), according to the pre-installed blotting protocol for high molecular weight proteins. The membrane was washed three times with $15 \mathrm{ml}$ Western Froxx washing solution (BioFroxx GmbH, Einhausen, Germany) for $5 \mathrm{~min}$, which was followed by primary antibody incubation at $4{ }^{\circ} \mathrm{C}$. A list of antibodies used for Western blot analysis is summarized in Table 5. The primary antibodies were diluted in a combined blocking and secondary antibody solution (WesternFroxx anti-Mouse HRP/anti-Rabbit HRP; BioFroxx GmbH, Einhausen, Germany). Calnexin was used as a reference protein. After the removal of the antibody solution, the membrane was incubated with $15 \mathrm{ml}$ washing solution three times. Protein band detection was performed with the
Western Lightning Plus Chemiluminescence Reagent (PerkinElmer Inc., Waltham, MA, USA). The chemiluminescence signal was detected using the ImageQuant LAS 400 (GE Healthcare, Chicago, USA). Thereafter, the membrane stripping was performed using the Western Froxx stripping solution (BioFroxx GmbH, Einhausen, Germany).

\section{ELISA}

Enzyme-linked immunosorbent assay (ELISA) was used to determine the IL-6 concentration of the cell culture supernatant (24 h and $48 \mathrm{~h}$ after experiments) and cell lysate (48 $\mathrm{h}$ after experiments).

The detection procedure was based on the sandwich ELISA technique's principle using the Human IL-6 Quantikine ELISA Kit (R\&D Systems, Minneapolis, USA), according to the provided instructions, at room temperature. Measurements were performed in duplicate with $100 \mu$ of the antigen-containing sample solution (cell culture supernatant or lysate). The quantitative detection of the IL- 6 concentration was measured by a Tecan Infinite F50 Absorbance Microplate Reader using a standard provided curve. Measured IL-6 concentrations were divided by the total protein concentrations to obtain the IL-6 concentration in picogram per milligram protein. The quotient (pg IL-6/mg protein) was used for further statistical analysis.
Table 5 Catalog number, manufacturer/distributor, and dilution of antibodies used for Western blot analysis

\begin{tabular}{llll}
\hline Antibody & $\begin{array}{l}\text { Catalog } \\
\text { number }\end{array}$ & Manufacturer (company, city, country) & Dilution \\
\hline Calnexin (anti-rabbit) & ADI-SPA-865 & $\begin{array}{l}\text { Enzo Life Sciences GmbH, Lörrach, } \\
\text { Germany } \\
\text { Cell Signaling Technology, MA, USA }\end{array}$ & $1: 1000$ \\
Collagen 1A1 (anti-rabbit) & 84336 & Abcam, Cambridge, UK & $1: 5000$ \\
Collagen 5A1 (anti-rabbit) & ab7046 & Abcam, Cambridge, UK & $1: 1000$ \\
$\begin{array}{l}\text { Inducible NO synthase (anti-rabbit) } \\
\text { Nuclear factor kappa B p65 } \\
\text { (anti-rabbit) }\end{array}$ & $\begin{array}{l}\text { ab3523 } \\
\text { Cell Signaling Technology, MA, USA }\end{array}$ & $1: 1000$ \\
\hline
\end{tabular}



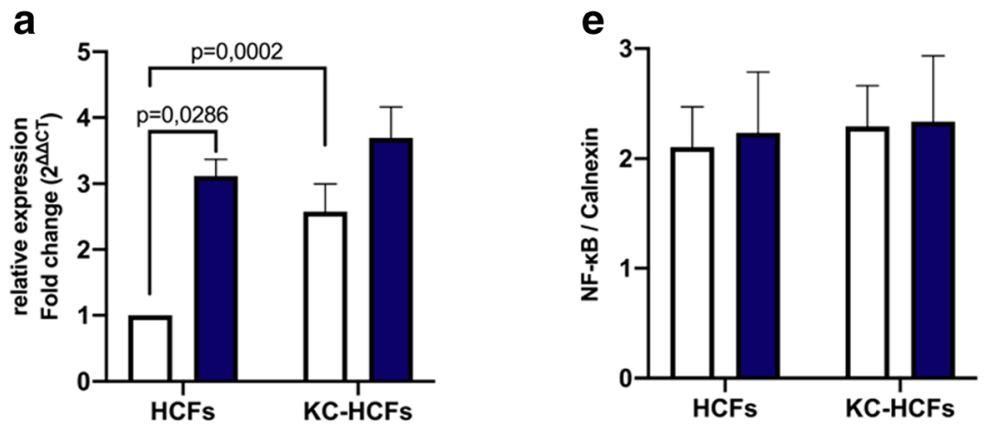

b

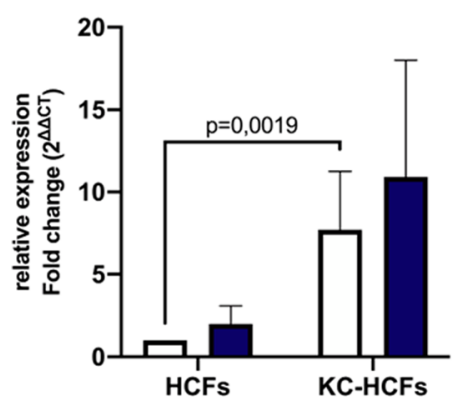

C

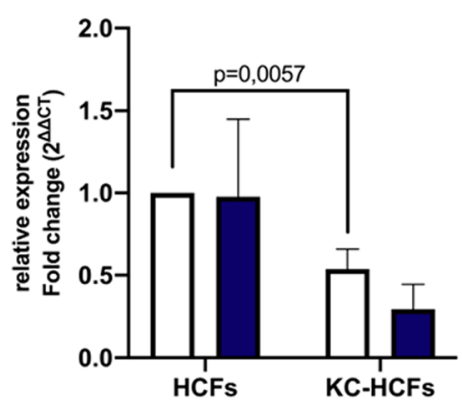

d

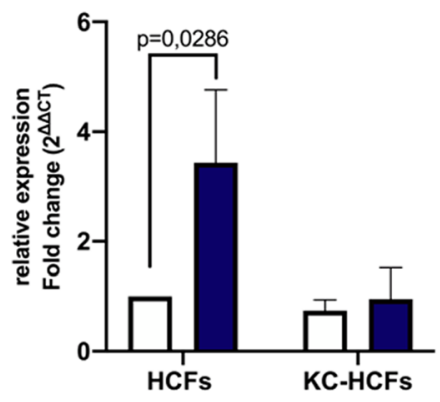

f
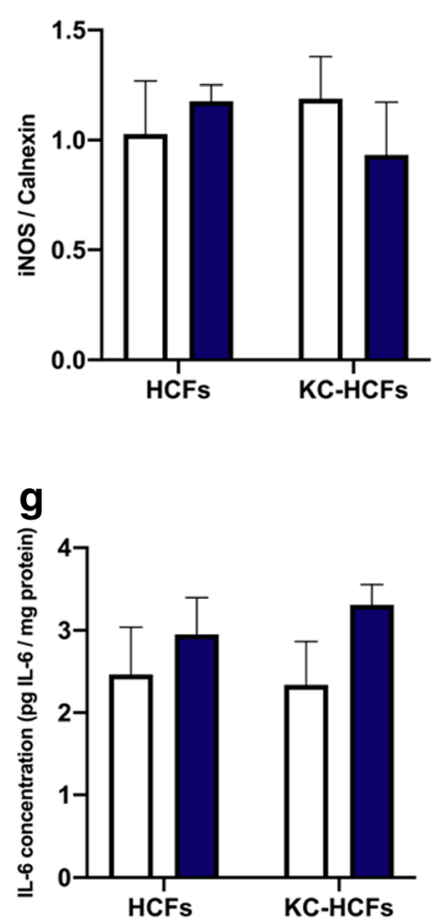

h

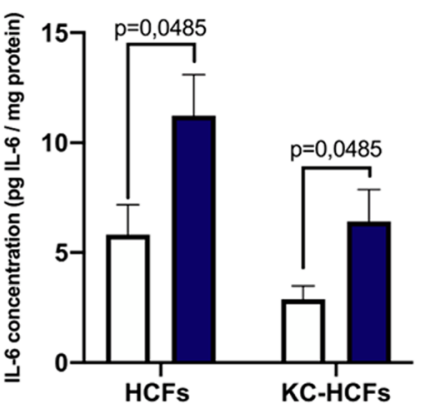

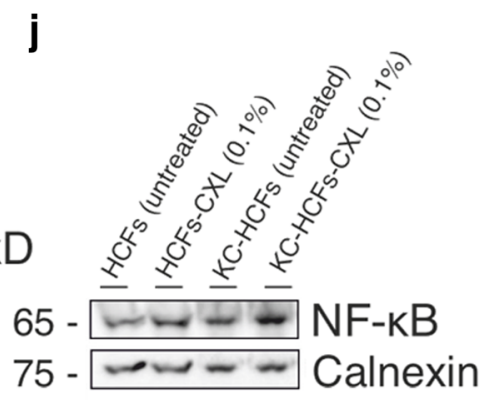

k

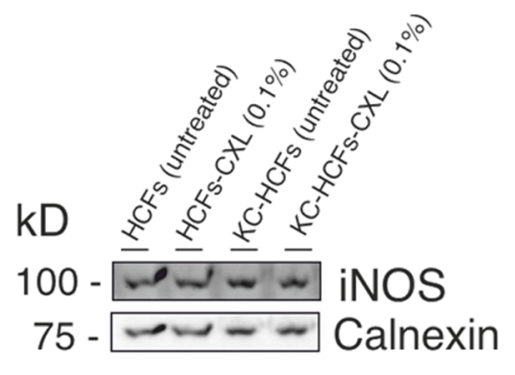

Untreated group

$0.1 \%$ riboflavin UV-A illumination

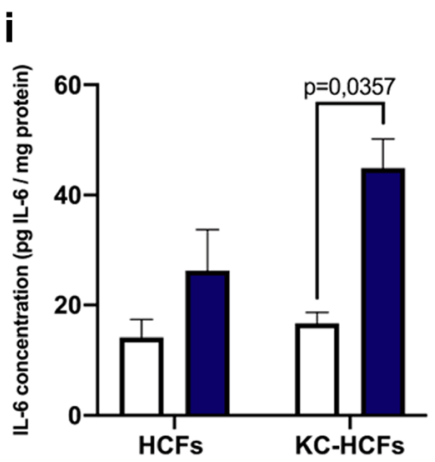


Fig. 1 Effect of riboflavin UV-A illumination on NF-kB, iNOS, and IL-6 mRNA and protein expression (untreated group: white bars; riboflavin UV-A illumination group: blue bars). NF-kB (24 h), iNOS (48 h), and IL-6 (24 h and $48 \mathrm{~h}$ ) gene expression was measured 24 or $48 \mathrm{~h}$ after riboflavin UV-A illumination. NF-kB and iNOS protein expression analysis was performed $48 \mathrm{~h}$ after riboflavin UV-A illumination. IL- 6 concentration of the cell culture supernatant $(24 \mathrm{~h}$ and $48 \mathrm{~h}$ after treatment) and cell lysate (48 h after treatment) was determined by ELISA. (A-D) NF- $\mathrm{kB}$, iNOS, and IL-6 quantitative mRNA analysis. Data show mean \pm SEM of at least 3 independent experiments in duplicate. (E, F) Relative quantification of NF- $\mathrm{KB}$ and iNOS Western blot analysis. Calnexin was used as loading control and to calculate the relative protein expression levels. Data show mean \pm SEM of at least 3 independent experiments in duplicate. (G-I) IL-6 concentration was determined in cell culture supernatant and cell lysate 24 and/or $48 \mathrm{~h}$ after riboflavin UV-A illumination. Measured IL- 6 concentrations were divided by the total protein concentrations, to obtain the IL- 6 concentration in pg per $\mathrm{mg}$ protein, these values are displayed (pg IL-6/mg protein). Data show mean \pm SEM of at least 3 independent experiments in duplicate. $(\mathrm{J}$, K) Representative NF- $\mathrm{kB}$ and iNOS Western blots. Significant $p$ values $(<0.05)$ are highlighted in the diagrams

\section{Statistical analysis}

GraphPad Prism 7.04 was used for the statistical analysis and for creating the diagrams. All data were expressed as mean \pm SEM. Difference between groups was determined using Mann-Whitney $U$ test. $p$ values $<0.05$ were considered statistically significant.

\section{Results}

\section{qPCR}

\section{Gene expression in untreated HCFs and KC-HCFs}

NF- $\kappa \mathrm{B}$ and iNOS mRNA expression was higher $(p=0.0002$; $p=0.0019)$ and IL-6 ( $p=0.0057)$ mRNA expression was lower in untreated $\mathrm{KC}-\mathrm{HCF}$ s than in untreated healthy controls (Fig. 1). Col 1 and Col 5 mRNA expression was higher in $\mathrm{KC}-\mathrm{HCFs}$ than in HCFs $(p=0.0019 ; p=0.0054)$ (Fig. 2).

\section{Gene expression in HCFs and KC-HCFs after riboflavin UV-A illumination}

NF- $\mathrm{KB}$ and IL-6 mRNA expression increased ( $p=0.0286$; $p=0.0286$ ) in HCFs after $0.1 \%$ riboflavin UV-A illumination. NF- $\mathrm{KB}$ and iNOS mRNA expression remained unchanged in KC-HCFs after treatment ( $p=0.2788$; $p=$ $0.7457)$ and iNOS mRNA expression did not change through $0.1 \%$ riboflavin UV-A illumination in HCFs or KC-HCFs $(p=0.3143)$ (Fig. 1).
Col 1 mRNA expression increased in HCFs following $0.1 \%$ riboflavin UV-A illumination $(p=0.0286)$ and Col 5 expression remained unchanged in HCFs and $\mathrm{KC}-\mathrm{HCF}$ s after treatment ( $p=0.0971 ; p=0.4623$ ) (Fig. 2).

\section{Western blot}

NF-kB $(p=0.7308)$, iNOS $(p=0.6282)$, Col $1(p=0.3660)$, and Col $5(p=0.1255)$ protein expression did not differ between untreated HCFs and KC-HCFs. NF-kB $(p=0.9999 ; p=$ $0.9999)$, iNOS $(p=0.9999 ; p=0.6667), \operatorname{Col} 1$ ( $p=0.3660 ; p$ $=0.5167)$, and Col $5(p=0.8571 ; p=0.5714)$ protein expression remained unchanged in HCFs or KC-HCFs through $0.1 \%$ riboflavin UV-A illumination (Figs. 1 and 2).

\section{ELISA}

IL-6 concentration in the cell culture supernatant did not differ between untreated HCFs and KC-HCFs ( $24 \mathrm{~h}: p=0.8785 ; 48$ $\mathrm{h}: p=0.0650)$. Twenty-four hours after treatment, IL-6 concentration in the cell culture supernatant did not change in $\mathrm{HCFs}$ and KC-HCFs $(p=0.4970 ; p=0.1333)$. Nevertheless, $48 \mathrm{~h}$ after $0.1 \%$ riboflavin UV-A illumination, IL-6 concentration in the cell culture supernatant increased in HCFs $(p=0.0485)$ and KC-HCFs $(p=0.0485)$, compared to baseline values (Fig. 1).

In the cell lysate, IL- 6 concentration did not differ between untreated HCFs and KC-HCFs $(p=0.7922)$. Nevertheless, in the cell lysate, IL-6 concentration increased in KC-HCFs $48 \mathrm{~h}$ after $0.1 \%$ riboflavin UV-A illumination $(p=0.0357)$. In HCFs, IL-6 concentration in the cell lysate remained unchanged after treatment $(p=0.1667)$ (Fig. 1).

\section{Discussion}

Little is known about the pathogenesis of $\mathrm{KC}$, but along the reported changes in collagen metabolism $[11,12]$, the suspicion of a chronic inflammatory component is increasingly coming to the fore. Since cross-linking was first introduced by Wollensak et al. in 2003 [16], it became an indispensable therapeutic option for treating ectatic corneal disorders. However, the cell biological effects after CXL were barely investigated. Therefore, in this study, we treated corneal fibroblasts in vitro with riboflavin UV-A illumination, to examine the impact of CXL regarding expression changes of inflammatory markers NF-kB, iNOS, IL-6, and collagen 1 and 5 in HCFs and KC-HCFs.

We could demonstrate changes in gene expression linked to inflammation in untreated KC-HCFs. NF- $\mathrm{KB}$ is an important modulator of many cell biological pathways through its influence on more than 500 genes, mainly genes associated with inflammatory responses [19]. Both iNOS and IL-6 are influenced by NF-KB [20, 21]. Additionally, iNOS is 
activated by IL-1, TNF- $\alpha$, and interferon- $\gamma$ and leads to the production of nitric oxygen as part of inflammatory processes [22]. Besides elevated inflammatory markers in the tear fluid of KC patients [7], Karamichos et al. reported an increase in metabolites associated with oxidative stress in $\mathrm{KC}$ keratocytes, which could be related to a chronic inflammatory condition [8]. We argue that increased iNOS mRNA expression in $\mathrm{KC}$-HCFs is due to underlying inflammatory processes in $\mathrm{KC}$, which may be induced by increased production of ROS and other metabolic pathway changes. In another study, KCHCFs showed an increased ROS production, through which these cells got more vulnerable to additional oxidative stress than HCFs [23]. As CXL itself results in oxidative stress [14], resulting in a secondary inflammatory reaction, we investigated its effects on HCFs and KC-HCFs. In a previous study of our research group, we demonstrated an increased apoptotic rate of stromal cells and reduced cell viability in $\mathrm{KC}-\mathrm{HCFs}$, after riboflavin UV-A illumination [17], whereas in another study, normal HCFs were less vulnerable [24]. Increased keratocyte apoptosis after CXL could also be demonstrated in $\mathrm{KC}$ corneas [25]. Myofibroblastic transformation following
CXL also differed significantly between $\mathrm{KC}$ and normal corneal stromal cells $[17,24]$.

In our present study, we could demonstrate that riboflavin UV-A illumination is associated with a significant increase in NF- $\mathrm{KB}$ and IL-6 mRNA expression in HCFs, but in KC-HCFs, no changes were detected. This could be related to an altered NF- $\mathrm{kB}$ and IL-6 mRNA expression in untreated KC-HCFs compared to untreated HCFs and may refer to an underlying cellular stress reaction in KC-HCFs [8], with an insufficient capacity of KC-HCFs to further increase gene expression, due to possibly restricted regulatory mechanisms. In a recently published study of our research group, we investigated the influence of hypoxic stress on HCFs and KC-HCF [18]. Interestingly, increased gene expression of inflammatory markers (NF- $\mathrm{KB}$ and iNOS) was only observed within the HCF group, whereas in KC-HCFs, gene expression was not influenced through hypoxia. Increased ROS production after riboflavin UV-A illumination, as well as hypoxia, could result in inflammatory reactions, but further investigation is necessary to clarify why changes in gene expression could not be measured in KC-HCFs after those specific stress stimuli.

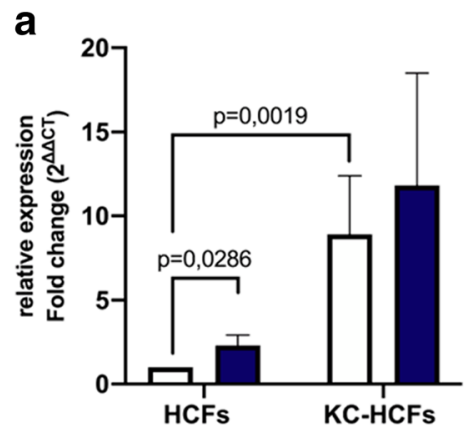

b

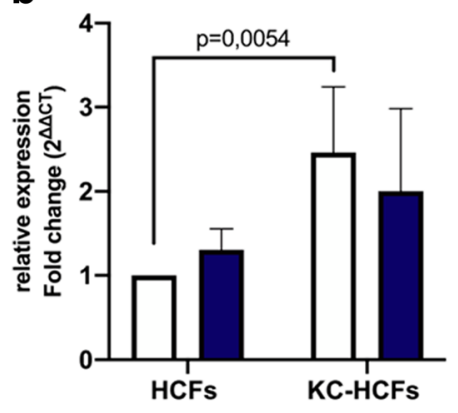

C

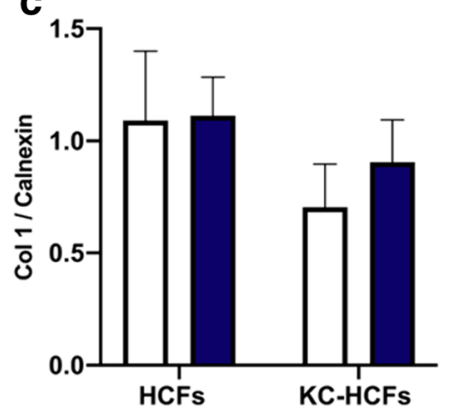

d

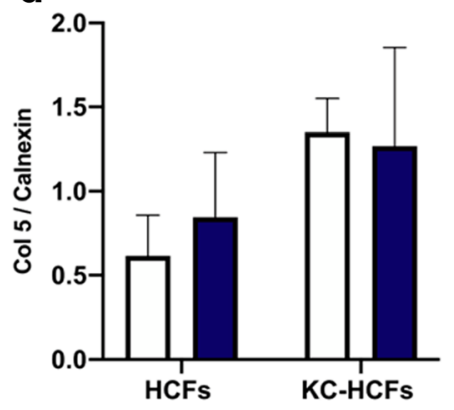

e

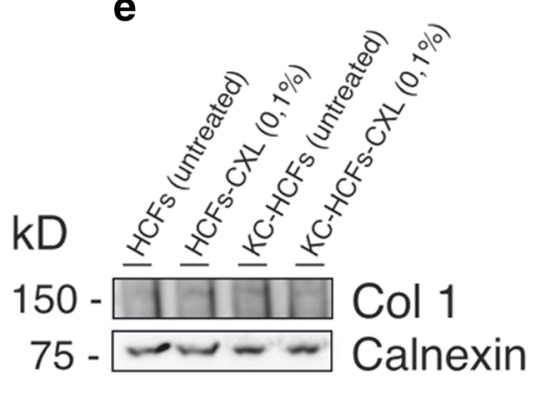

f

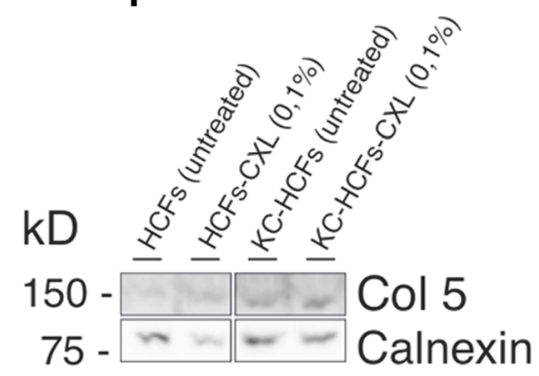

$\square$ Untreated group

\section{$0.1 \%$ riboflavin UV-A illumination}

Fig. 2 Effect of riboflavin UV-A illumination on Col 1 and Col 5 mRNA and protein expression (untreated group: white bars; riboflavin UV-A illumination group: blue bars). Col 1 and Col 5 mRNA expression was measured $24 \mathrm{~h}$ after riboflavin UV-A illumination. The protein expression analysis was performed $48 \mathrm{~h}$ after treatment. (A, B) Col 1 and Col 5 quantitative mRNA analysis. Data show mean \pm SEM of at least 3 independent experiments in duplicate. (C, D) Relative quantification of Col 1 and Col 5 Western blot analysis. Calnexin was used as loading control and to calculate the relative protein expression levels. (E, F) Representative Col 1 and Col 5 Western blots. Significant $p$ values $(<$ 0.05 ) were highlighted in the diagrams 
Although no IL-6 mRNA expression changes in KC-HCFs could be measured after riboflavin UV-A illumination, IL-6 protein amount increased significantly in the cell culture supernatant through riboflavin UV-A illumination in both HCFs and $\mathrm{KC}-\mathrm{HCF}$. However, a difference in the IL-6 concentration of the cell culture supernatant could only be observed after $48 \mathrm{~h}$, indicating that this might be a delayed reaction of the corneal fibroblasts after riboflavin UV-A illumination, which should be considered in future studies. Interestingly, riboflavin UV-A illumination resulted in an increased intracellular IL-6 concentration only in KC-HCFs, which was not accompanied by altered mRNA expression. This could indicate that KC-HCFs can only partially compensate the induced stress stimulus and therefore have a significant intracellular stress response.

In this study, corneas with advanced $\mathrm{KC}$ stages (Belin $\mathrm{KC}$ classification) and corneal scarring were used [26]. Most interestingly, we detected an increased Col 1 and Col 5 mRNA expression in $\mathrm{KC}$-HCFs compared to $\mathrm{HCFs}$, which refers to the disturbance of the collagen metabolism in KC corneas [11, 12]. In addition, the Col 1 and Col 5 mRNA expression values have shown a larger variability in KC-HCFs than in HCFs. These variable values were confirmed through repeat measurements. We suggest that these differences depend on the individual patient's cornea and in addition, during $\mathrm{KC}$ progression, gene expression could also change. It is important to investigate these results in future studies, for example, by comparing the mRNA and protein expression of $\mathrm{KC}$ corneas with or without scars or under consideration of the $\mathrm{KC}$ stage.

Furthermore, we investigated whether CXL is associated with changes in collagen expression. In this study, we observed increased Col 1 mRNA expression only in HCFs without significant protein expression changes in HCFs or KCHCFs following riboflavin UV-A illumination. Another study described a significant $\mathrm{Col} 1$ and $\mathrm{Col} 5$ protein expression decrease after $0.1 \%$ riboflavin UV-A illumination in $\mathrm{KC}$ HCFs, but not in HCFs, nevertheless, using 3D cell cultures [27]. To which extent these changes could be of cell biological or clinical relevance must be critically analyzed.

Finally, it is necessary to mention certain limitations of our study concerning the interpretation of the results. On the one hand, the avascular stroma represents a nutrient-poor tissue. Therefore, in vitro experiments are not equally applicable to in vivo models. Our isolated keratocytes dedifferentiated into fibroblasts during cell cultivation, using FCS, which could probably have a significant impact on gene and protein expression. The results of the 2D culture are also not directly transferable to the in vivo model, but give a good indication for further studies. In addition, there is no suitable in vivo model or animal model to study KC. In summary, we found expression differences between untreated and treated corneal fibroblasts, which is an important input for future studies.

\section{Conclusions}

In this study, altered mRNA expression of the inflammatory markers (NF-kB, iNOS, IL-6), as well as the collagens (Col 1, Col 5), could be detected in untreated KC-HCFs. Riboflavin UV-A illumination resulted in significant gene expression changes only in HCFs. Increased IL-6 concentrations in the cell culture supernatant (HCFs and KC-HCFs) and cell lysate (KC-HCFs) indicated an inflammatory response after this treatment. The effects of cross-linking on gene and protein expression have rarely been investigated, and therefore, the results of this study provide a basis for further research projects.

Acknowledgments The work of Dr. Tanja Stachon, Dr. Lorenz Latta, and Prof. Dr. Nóra Szentmáry at the Dr. Rolf M. Schwiete Center for Limbal Stem Cell and Aniridia Research was supported by the Dr. Rolf M. Schwiete Foundation. We would like to thank Prof. Dr. Veit Flockerzi (Department of Experimental and Clinical Pharmacology, Institute of Experimental and Clinical Pharmacology and Toxicology, Center for Molecular Signaling (PZMS), Saarland University, Homburg, Germany) for the use of the Western blot visualization system.

Funding information Open Access funding enabled and organized by Projekt DEAL.

\section{Compliance with ethical standards}

Conflict of interest The authors declare that they have no conflict of interest.

Ethics approval and consent to participate This study was performed in accordance with the Declaration of Helsinki and was approved by the Ethics Committee of Saarland/Germany (No. 41/18). An informed consent was obtained from all participants with $\mathrm{KC}$, before keratoplasty was performed.

Open Access This article is licensed under a Creative Commons Attribution 4.0 International License, which permits use, sharing, adaptation, distribution and reproduction in any medium or format, as long as you give appropriate credit to the original author(s) and the source, provide a link to the Creative Commons licence, and indicate if changes were made. The images or other third party material in this article are included in the article's Creative Commons licence, unless indicated otherwise in a credit line to the material. If material is not included in the article's Creative Commons licence and your intended use is not permitted by statutory regulation or exceeds the permitted use, you will need to obtain permission directly from the copyright holder. To view a copy of this licence, visit http://creativecommons.org/licenses/by/4.0/.

\section{References}

1. Fan Gaskin JC, Patel DV, McGhee CNJ (2014) Acute corneal hydrops in keratoconus - new perspectives. Am J Ophthalmol 157:921-928. https://doi.org/10.1016/j.ajo.2014.01.017

2. Rabinowitz YS (1998) Keratoconus. Surv Ophthalmol 42:297319. https://doi.org/10.1016/S0039-6257(97)00119-7 
3. Godefrooij DA, de Wit GA, Uiterwaal CS et al (2017) Age-specific incidence and prevalence of keratoconus: a nationwide registration study. Am J Ophthalmol 175:169-172. https://doi.org/10.1016/j. ajo.2016.12.015

4. Cozma I, Atherley C, James N (2005) Influence of ethnic origin on the incidence of keratoconus and associated atopic disease in Asian and white patients. Eye (Lond) 19:924-925. https://doi.org/10. 1038/sj.eye.6701677

5. Romero-Jiménez M, Santodomingo-Rubido J, Wolffsohn JS (2010) Keratoconus: a review. Contact Lens Anterior Eye 33: 157-166. https://doi.org/10.1016/j.clae.2010.04.006

6. Stachon T, Latta L, Kolev K et al (2019) Increased NF-KB and iNOS expression in keratoconus keratocytes - hints for an inflammatory component? Klin Monbl Augenheilkd. https://doi.org/10. 1055/a-1002-0100

7. Lema I, Durán JA (2005) Inflammatory molecules in the tears of patients with keratoconus. Ophthalmology 112:654-659. https:// doi.org/10.1016/j.ophtha.2004.11.050

8. Karamichos D, Hutcheon A, Rich C et al (2014) In vitro model suggests oxidative stress involved in keratoconus disease. Sci Rep 4:4608. https://doi.org/10.1038/srep04608

9. Karamichos D, Zieske J, Sejersen H et al (2015) Tear metabolite changes in keratoconus. Exp Eye Res 132:1-8. https://doi.org/10. 1016/j.exer.2015.01.007

10. Hassell J, Birk D (2010) The molecular basis of corneal transparency. Exp Eye Res 91:326-335. https://doi.org/10.1016/j.exer. 2010.06.021

11. Hayes S, Boote C, Tuft S et al (2007) A study of corneal thickness, shape and collagen organisation in keratoconus using videokeratography and X-ray scattering techniques. Exp Eye Res 84:423-434. https://doi.org/10.1016/j.exer.2006.10.014

12. Alkanaan A, Barsotti R, Kirat O et al (2019) Collagen fibrils and proteoglycans of peripheral and central stroma of the keratoconus cornea - ultrastructure and 3D transmission electron tomography. Sci Rep 9:1-11. https://doi.org/10.1038/s41598-019-56529-1

13. Parker JS, van Dijk K, Melles GRJ (2015) Treatment options for advanced keratoconus: a review. Surv Ophthalmol 60:459-480. https://doi.org/10.1016/j.survophthal.2015.02.004

14. Raiskup F, Spoerl E (2013) Corneal crosslinking with riboflavin and ultraviolet A. I. principles. Ocul Surf 11:65-74. https://doi. org/10.1016/j.jtos.2013.01.002

15. Juarranz A, Jaén P, Sanz-Rodriguez F, Cuevas-Santos J (2008) Photodynamic therapy of cancer. Basic principles and applications. Clin Transl Oncol 10:148-154. https://doi.org/10.1007/s12094008-0172-2

16. Wollensak G, Spoerl E, Seiler T (2003) Riboflavin/ultraviolet-Ainduced collagen crosslinking for the treatment of keratoconus. Am
J Ophthalmol 135:620-627. https://doi.org/10.1016/S00029394(02)02220-1

17. Song X, Stachon T, Wang J et al (2015) Viability, apoptosis, proliferation, activation, and cytokine secretion of human keratoconus keratocytes after cross-linking. Biomed Res Int 2015:254237. https://doi.org/10.1155/2015/254237

18. Stachon T, Latta L, Seitz B, Szentmáry N (2020) Hypoxic stress increases NF- $\mathrm{KB}$ and iNOS mRNA expression in normal, but not in keratoconus corneal fibroblasts. Graefe's Arch Clin Exp Ophthalmol. https://doi.org/10.1007/s00417-020-04900-8

19. Gupta SC, Sundaram C, Reuter S, Aggarwal BB (2010) Inhibiting NF- $\mathrm{KB}$ activation by small molecules as a therapeutic strategy. Biochim Biophys Acta - Gene Regul Mech 1799:775-787. https://oi.org/10.1016/j.bbagrm.2010.05.004

20. Libermann TA, Baltimore D (1990) Activation of interleukin-6 gene expression through the NF-kappa B transcription factor. Mol Cell Biol 10:2327-2334. https://doi.org/10.1128/mcb.10.5.2327

21. Morris KR, Lutz RD, Choi HS et al (2003) Role of the NF-kB signaling pathway and $\mathrm{KB}$ cis-regulatory elements on the IRF-1 and iNOS promoter regions in mycobacterial lipoarabinomannan induction of nitric oxide. Infect Immun 71:1442-1452. https://doi. org/10.1128/IAI.71.3.1442-1452.2003

22. Donnelly LE, Barnes PJ (2002) Expression and regulation of inducible nitric oxide synthase from human primary airway epithelial cells. Am J Respir Cell Mol Biol 26:144-151. https://doi.org/10. 1165/ajrcmb.26.1.4477

23. Chwa M, Atilano SR, Reddy V et al (2006) Increased stressinduced generation of reactive oxygen species and apoptosis in human keratoconus fibroblasts. Invest Ophthalmol Vis Sci 47: 1902-1910. https://doi.org/10.1167/iovs.05-0828

24. Stachon T, Wang J, Song X et al (2015) Impact of crosslinking/ riboflavin-UVA-photodynamic inactivation on viability, apoptosis and activation of human keratocytes in vitro. J Biomed Res 29:321325. https://doi.org/10.7555/JBR.29.20130173

25. Messmer E, Meyer P, Herwig-Carl M et al (2012) Morphological and immunohistochemical changes after corneal cross-linking. Cornea 32: 111-117. https://doi.org/10.1097/ICO.0b013e31824d701b

26. Belin MW, Duncan JK (2016) Keratoconus: the ABCD Grading System. Klin Monbl Augenheilkd 233:701-707. https://doi.org/10. 1055/s-0042-100626

27. Sharif R, Hjortdal J, Sejersen H et al (2017) Human in vitro model reveals the effects of collagen cross-linking on keratoconus pathogenesis. Sci Rep 7:12517. https://doi.org/10.1038/s41598-01712598-8

Publisher's note Springer Nature remains neutral with regard to jurisdictional claims in published maps and institutional affiliations. 